BRASIL, TURQUIA: algumas lições de Junho de 2013

\title{
Thomas Coutrot
}

Association pour la Taxation des Transactions Financières et pour l'Action Citoyenne-France

BRASIL, TURQUIA: algumas lições de Junho de 2013

Resumo: O artigo faz uma breve análise da conjuntura do capitalismo mundial em crise e das estratégias dos países emergentes para perpetuar as suas taxas de crescimento. Destaca o caráter predatório, ecologicamente incorreto e desigual do desenvolvimento dessas economias emergentes do início do século XXI. Apresenta os movimentos democráticos das multidões de diferentes países, destacadamente da Tunísia, Turquia e Brasil. Enfâse analítca na última experiência recente brasileira, o movimento de junho de 2013. Discussão em torno do "despertar político global" para a consolidação de um modelo de sociedade mais democrático, de respeito aos direitos dos seus cidadãos.

Palavras-chave: Crise, países emergentes, movimentos, democracia.

BRAZIL, TURKEY: some lessons from June 2013

Abstract: The article makes a brief analysis of the global crisis of capitalism and the strategies of emerging countries to perpetuate their growth rates. Highlights the predatory nature, ecologically incorrect and uneven development of these emerging economies of the beginning of twenty-first century. Displays the democratic' movements of crowds of different countries, notably in Tunisia, Turkey and Brazil. Analytic emphasis on the last recent experience, the brazilian movement in June 2013. Discussion on "global political awakening" to consolidate a model of society more democratic, respect the rights of its citizens.

Keywords: Crisis, emerging countries, movements, democracy. 


\section{INTRODUÇÃO}

Os países emergentes estão sendo alcançados pela crise global. A fuga de capitais, a queda dos mercados de ações e divisas: o anúncio da mudança de rumo do Fed, o banco central estadunidense, provocou turbulências nos mercados financeiros indianos, brasileiros, turcos, sul-africanos. O capital financeiro norte-americano, antecipando-se a elevação das taxas de juros, decidiu voltar a Wall Street. O Dow Jones recuperou assim a sua exuberância irracional, superando o recorde estabelecido em 2006, o que não é um bom presságio.

O tornado financeiro voltarà em breve para o Norte. Mas os anúncios do Fed são apenas um epifenômeno. As dificuldades econômicas dos emergentes já tinham começado antes, revelando as bases precárias de seus modelos de crescimento. Mais importante do que a crise financeira, os grandes movimentos sociais vividos pelo Brasil e pela Turquia em junho passado expuseram as limitações destes modelos.

\section{PADRÕES INSUSTENTÁVEIS}

Impulsionado pelas exportações de matériasprimas e produtos agrícolas para a China, a economia do Brasil cresceu e os salários reais aumentaram ao longo da década de 2000. As desigualdades sociais diminuiram ligeiramente devido a uma política inteligente de redistribuição, mas continuam entre as mais altas do mundo. O crescimento do Brasil é um impasse: ecologicamente predatório (monocultura de soja OGM e cana-de-açúcar, extrativismo), favorece a especulação fundiária e a proliferação de automóveis particulares obtidos a crédito, tornando as cidades inferno de poluição e engarrafamentos. As exportações são principalmente de matériasprimas e agrícolas, marcando o declínio do país na divisão internacional do trabalho. O boom da exportação primária sustentou temporariamente o crescimento nos anos Lula, mas é prejudicado pela falta de infra-estrutura (incluindo o transporte) e a desaceleração do comércio mundial após a crise de 2008. Claro que, em vinte anos, as favelas deram lugar a casas mais decentes, e o medo da fome caiu drasticamente sob o impacto de movimentos de cidadãos revezados por políticas públicas (Fome Zero). Mas os edifícios de luxo retrancados se multiplicaram, mostrando aos olhos de todos uma situação de apartheid social mantida.

A Turquia é muito menos dotada de recursos naturais e experimentou um enorme déficit comercial estrutural. Mas também aqui o motor do crescimento é carro e concreto. Os projetos gigantescos do primeiro-ministro Erdogan - o da Praça Taksim é o mais conhecido, mas o projeto de construção do maior aeroporto do mundo em Istambul é ainda mais louco - recordam as obras gigantescas da Copa do mundo e dos Jogos Olímpicos no Brasil. Essas grandes obras inúteis foram um dos gatilhos dos movimentos nos dois países em junho deste ano. A especulação puxa os preços dos imóveis e aluguéis para cima:

[...] provavelmente não é coincidência que ambos os países que estão experimentando agitação social - Brasil e Turquia - estejam no topo do ranking dos doze países em que se verificam os maiores aumentos nos preços da habitação em todo o mundo em 2012. (DENOUNE, 2013).

A bolha imobiliária poderá explodir no Brasil após anos de inchamento. Quanto aos serviços de educação e saúde públicas, eles permanecem miseráveis, enquanto as escolas e clínicas privadas prosperam praticando preços exorbitantes.

A esquerda brasileira, dominada pelo PT de Lula, no poder há 10 anos, perdeu a sua capacidade de inovar. O PT está integrado num sistema político clientelista e corrupto que ele renunciou a reformar. Até a esquerda radical mantém uma visão produtivista do progresso, torcendo, por exemplo, pela exploração das grandes jazidas de petróleo não convencional em águas profundas encontradas fora do Rio de Janeiro. A esquerda turca, por sua vez, não consegue se desprender de arcaísmos stalinistas e /ou nacionalistas.

Brasil e Turquia - e a situação é semelhante na China - enfrentam as contradições do modelo capitalista de produção: as desigualdades sociais explosivas, a profunda crise ecológica urbana e rural, mas também, conforme demonstrado pelos recentes movimentos, a negação diária das aspirações democráticas. A crise econômica e financeira iminente poderá provocar terremotos políticos em que as aspirações populares pou uma democracia real desempenharão um papel decisivo.

\section{MOVIMENTOS (RE) FUNDADORES}

Enquanto boa parte da esquerda brasileira interpreta de modo bastante provinciano o junho brasileiro como o movimento confuso duma classe média despolitizada, ou até manipulada pela direita, minha interpretação é completamente diversa: não se pode entender esse movimento sem colocálo numa perspectiva global. O paralelo com a Turquia pode ajudar a esclarescer esse ponto. Pois os movimentos turcos e brasileiros marcam a entrada desses dois grandes países emergentes na dança dos movimentos democráticos de multidões iniciado pela Tunísia em dezembro de 2010. Estes movimentos compartilham muitas características, de modo que se pode falar de uma onda global de uma magnitude comparável apenas ao maio de 1968. Mas ao contrário de 1968, quando os grandes movimentos de massa ocorreram ao longo de um período de alguns meses, a seqüência temporal 
aberta pela revolução tunisiana - ou até mesmo pela revolução verde no Irã, em 2009 - já é muito mais longa e leva características inéditas.

É claro que as metas e os modos de ação específicos podem variar de país para país ${ }^{1}$. Alguns movimentos se opõem às ditaduras (Tunísia, Egito, Síria) e procuram a sua derrubada. Outros ocorrem em países (Argentina, Rússia, Senegal, Turquia) onde as eleições são aparentemente livres, contra o autoritarismo, nepotismo e /ou regimes políticos corruptos, ou contra a manipulação eleitoral. Outros, especialmente na Europa e EUA, se opõem às políticas neoliberais de austeridade e desregulação do trabalho, a energia, os bancos, as desigualdades sociais se tornam exorbitantes (1\% contra 99\%). Em alguns casos, os movimentos têm como alvo, grandes projetos inúteis e antiecológicos: esta dimensão tem sido especialmente importante na Turquia (destruição do Parque Gezi em Taksim) e no Brasil (obras da Copa do Mundo e das Olimpíadas).

No entanto as semelhanças superam as diferenças. Podemos distinguir pelo menos quatro traços comuns: a auto-organização, a reconquista democrática do espaço e do tempo, a crítica radical da representação, a prática concreta da igualdade política.

1. Os movimentos se desenvolvem independentemente dos principais sindicatos ou organizações políticas, sendo espontaneamente auto-organizados. Os pequenos grupos de militantes, muitas vezes organizados de modo horizontal e não hierárquico (Juventud sin Futuro ou Democracia Real Ya na Espanha, Geração à Rasca em Portugal, Passe Livre no Brasil, Taksim Dayanışması na Turquia) podem servir como detonadores com suas palavras de ordem ou ações, mas podem ser rapidamente ultrapassados pela escala de mobilização que eles não controlam de modo algum. Na quase ausência de qualquer organização prévia, é o uso das redes sociais eletrônicas que permite uma coordenação em tempo real entre os atores desses movimentos. Obviamente estes movimentos não têm suas origens na tecnologia, mas eles confirmam o poder da Internet e dos celulares para facilitar o processo de auto-organização horizontal. Organizações já estabelecidas - sindicatos, associações, partidos de esquerda - na melhor das hipóteses tentam agarrar-se ao movimento, na pior, se opõem frontalmente, mas nunca conseguem controlar a dinâmica. Permanece sem resposta voltaremos à esse assunto - a questão da inscrição dos movimentos no tempo longo se eles se recusarem à qualquer forma de institucionalização.
2 Os movimentos procedem pela ocupação prolongada de espaços públicos notadamente praças. Essas ocupações têm como função principal de ancorar geograficamente e assegurar a visibilidade do movimento. Mas fundamentalmente, trata-se de demonstrar que as questões colocadas referem-se a toda a comunidade política, o povo. Trata-se de reapropriarse não somente do espaço, mas também do tempo da democracia, contra a lógica mediática e econômica da emergência permanente. As assembleias populares realizadas nas praças tomam o tempo para a expressão dos indivíduos e a construção do comum. As ações são decididas em público, às vezes após longa deliberação, mesmo que o consenso somente seja necessário entre os participantes da ação. $\mathrm{Na}$ Turquia, mesmo após a expulsão dos ocupantes do Parque Gezi, muitas cidades têm experimentado ocupações de parques e assembleias populares. No Brasil, o movimento tomou principalmente a forma de grandes manifestações, mas foi seguido por muitas ocupações especialmente de prefeituras e câmaras municipais que decidiram os aumentos de preços.

3 Todos os movimentos têm como alvo principal ou importante os representantes eleitos (quando não se trata de ditadores). As queixas variam em detalhes - a corrupção, o autoritarismo, a fraude, a submissão aos poderes econômicos -, mas referemse à substância da traição da promessa representativa: vocês não nos representam, o slogan dos indignados espanhóis, expressa um sentimento amplamente compartilhado. O caso brasileiro é emblemático: enquanto o PT foi formado na década de 1980 com a emanação dos movimentos sociais e populares, o alvo dos manifestantes era muitas vezes os prefeitos do Partido dos Trabalhadores, que decidiram (como São Paulo) pelo aumento dos custos das tarifas do transporte público para os usuários deste.

A crítica dos representantes vai muito além de uma revolta contra líderes injustos ou autoritários. Centra-se no princípio da representação como portador de uma ruptura radical entre representantes e representados. Os movimentos recusam a equação imposta pelos modernos entre democracia e representação, e se reconectam com a aspiração da velha participação direta de todos nas decisões. A profundidade e a radicalidade dessa crítica se manifesta 
nitidamente nas formas organizacionais concretas adotadas.

4. Os movimentos de fato se recusam a ser representados por porta-vozes ou líderes que iriam se colocar acima da massa. Para o desgosto dos meios de comunicação, que sempre tentam encenar figuras fotogênicas, ninguém diz representar os outros participantes, cada um fala em seu nome. Quando se deve delegar tarefas de representação aos indivíduos, por exemplo, para negociar com as autoridades, a delegação é estritamente controlada e efêmera, a rotação é a regra. A convite da presidenta Dilma Rousseff, o Movimento Passe Livre, que foi a origem das manifestações em junho no Brasil, afirmou:

\begin{abstract}
"Somos um movimento social autônomo, horizontal e apartidário, que jamais pretendeu representar o conjunto de manifestantes que tomou as ruas do país. Nossa palavra é mais uma dentre aquelas gritadas nas ruas, erguidas em cartazes, pixadas nos muros." (Informação verbal).
\end{abstract}

Recusando-se qualquer confisco, os movimentos implementam técnicas de distribuição igualitária da palavra nas reuniões. As mulheres estão em toda parte, presente em igualdade com os homens, inclusive em países muçulmanos. Na Turquia, The Economist notou com espanto que havia tantas mulheres como homens:

[...] "cenas em que jovens tatuados ajudam as mulheres veladas afetadas por gás lacrimogêneo são difíceis de conciliar com o clichê da laicidade que se opõe ao Islã.(THE NEW, 2013).

A periferia nunca dormiu, disseram muitos manifestantes brasileiros, se contrapondo às manchetes O Brasil acordou: as camadas populares não estão ausentes ${ }^{2}$, mesmo que os iniciadores sejam na maioria das vezes, jovens estudantes ou licenciados precários ou desempregados. Estes movimentos não se reivindicam duma classe ou duma causa específica - o feminismo, a ecologia -, mas expressam a aspiração de cada um para exercer seus direitos como cidadão, a ter sua voz ouvida, a controlar os seus representantes. Estes não são movimentos de classe, grupos sociais ou grupos de pressão, mas movimentos de indivíduos portadores dos direitos da cidadania democrática.

\section{O “DESPERTAR POLÍTICO GLOBAL"}

Os movimentos estão enraizados numa opinião comum: a relação entre representantes e representados, que sempre tem sido problemática na história da democracia parlamentar, já se desintegrou. A concentração do poder econômico levou a uma profunda transformação do Estado e enfraqueceu a sua legitimidade.

O Estado, numa sociedade dominada pelo capitalismo, está a serviço da reprodução social e acumulação de capital. Este é um estado capitalista. Mas, como muitas vezes lembra Gus Massiah, citando Engels, "[...] para ser um Estado de classe, o Estado também deve ser outra coisa que não um Estado de classe."

Aautonomia relativa do aparelho de Estado lhe permite incorporar compromissos institucionalizados entre interesses conflitantes. E o estado de bemestar (a mão esquerda do Estado, como diria Bourdieu) na Europa garante uma série de direitos que não são diretamente funcionais em termos de acumulação capitalista, e são cada vez menos.

No entanto, a colonização do Estado pela alta finança, a fusão das elites públicas e financeiras $^{3}$, a internacionalização antidemocrática do Estado, através da construção de instituições supranacionais não eleitas com poderes soberanos (Comissão Europeia, FMI, Banco Mundial, OMC...), reduziram drasticamente a capacidade de mediação e conciliação, enfraquecendo os compromissos sociais institucionalizados no estado de bem-estar.

Nos países emergentes, o estado de bemestar nunca adquiriu qualquer autonomia real, a protecção social e os serviços públicos continuam pífios. No Brasil o PT conquistou o poder no nível federal, mas não questionou o modelo econômico; o início de redistribuição de renda - Bolsa Família, aumento do salário mínimo - durante os mandatos de Lula reduziu marginalmente a distribuição desigual da riqueza, que continua a figurar entre as piores do mundo. O modelo político baseado no clientelismo e na corrupção institucionalizada manteve-se inalterado. A mesma continuidade prevalece na Turquia, onde o autoritarismo islâmico-conservador seguiu o autoritarismo Kemalista sem alterar um modelo de crescimento fundamentado em grandes projetos megalomaníacos, desigualdade e dívidas.

Em termos gerais, essa dominação reforçada do Estado pelas oligarquias é politicamente explosiva, porque contradiz uma tendência essencial das sociedades contemporâneas, a hegemonia da ideologia da justiça democrática. Nunca na história os valores fundamentais da democracia têm sido tão profundamente enraizados nos povos num número tão grande de países. Este despertar político global teorizado por Z. Brzeszinski (2005) significa que centenas de milhões de pessoas aspiram a se tornarem cidadãos ativos e reivindicam o cumprimento das promessas democráticas contidas nas constituições dos Estados ${ }^{4}$.

Segundo Brzeszinski (2005),

[...] a democracia sem uma justiça social para todos era possível na era 
aristocrática, não está mais na idade do despertar político das massas [...]".

Em que uma agenda reformista diz que "a promoção da democracia deve estar diretamente relacionada com a erradicação da extrema pobreza e a redução das desigualdades globais." Mas as oligarquias americanas e globais têm feito precisamente a escolha oposta com o projeto neoliberal, que tem continuado por 30 anos concentrando o poder e aumentando a desigualdade, de modo mais acelerado desde a crise de 2008.

A concentração sem precedentes de poder econômico e sua fusão com os poderes políticos não podem mais ser revertidas por uma elite autorreformista. O próprio conceito de democracia forjado pelas revoluções burguesas aparece exausto. O sistema parlamentar permitiu que o capitalismo fizesse um compromisso com a democracia. Um compromisso certamente instável e tempestuoso, pontuado por episódios autoritários ou fascistas, mas que apareceu após a queda da União Soviética, como um insuperável fim da história. No entanto, as pessoas estão redescobrindo o caráter oligárquico da representação, o que era óbvio para os filósofos iluministas e revolucionários do século XVIII ${ }^{5}$.

\section{UMA "DEMOCRACIA DOS MODERNOS" SEM FÔLEGO}

Para Benjamin Constant, grande teórico da democracia burguesa, enquanto a democracia dos antigos era baseada na participação efetiva e cotidiana dos cidadões nas decisões políticas, e ignorava a noção de representação política ${ }^{6}$, a democracia dos modernos dá toda licença para os eleitos governarem imunes à pressão popular. $\mathrm{O}$ contrapeso ao poder político dos representantes é o poder econômico da sociedade civil, ou seja, dos burgueses livres das tarefas de gestão política e dedicando-se apenas a seus negócios lucrativos. Os cidadãos aceitam deixar a classe política gerenciar os negócios do Estado, desde que sua situação financeira melhore gradualmente. Passividade política em troca de crescimento econômico: esta é a estrutura do tradeoff entre a democracia e o capitalismo, ilustrada hoje até a caricatura pelo sistema político chinês.

Neste compromisso, o Estado, relativamente autônomo em relação ao capital, tem a tarefa de promover a acumulação mantendo o equilíbrio social. Em formações sociais periféricas dominadas, esta autonomia do Estado permitiu ocasionalmente o surgimento de um poder forte, de caráter modernizante, acima das classes sociais, instigador de compromisso social (Atatürk , Getulio Vargas... ).

Mas, com o neoliberalismo, a liberalização dos movimentos de capitais e a colonização do Estado pela finança, a autonomia do poder político face ao poder econômico tem sido drasticamente reduzida.
Todas as políticas são possíveis desde que obedecem aos interesses do setor financeiro. A participação dos salários na renda nacional caiu em toda parte ${ }^{8}$. Os ganhos de produtividade desaceleram, e os que restam são monopolizados pelos acionistas em detrimento da grande massa da população.

Mas o compromisso entre capitalismo e democracia é fundamentado sobre o crescimento econômico. Só ele permite cumprir a promessa de melhores ganhos privados para todos. Eis porque a obsessão das elites políticas com o crescimento é mais forte do que nunca, apesar dos desastres ecológicos que esse crescimento traz consigo.

Sob a influência do neoliberalismo, até 2008, o endividamento das famílias substituiu os salários para estimular a demanda em países ricos (déficitários), enquanto os emergentes (superavitários) foram puxados pelas suas exportações. Uma vez que a desaceleração do comércio mundial reduziu as exportações dos países emergentes, a dívida do governo e das famílias tornou-se finalmente a principal fonte de crescimento da demanda no Sul ${ }^{12}$, com o risco de bolha já mencionado. Depois do Japão no final de 1980, o estouro das bolhas que ocorreu em 2007-2008 nos países do centro (EUA, Espanha, Reino Unido, Irlanda) mostrou as conseqüências desastrosas e duradouras de um krach imobiliário e bancário. A escassez dos recursos não renováveis , a exploração excessiva dos recursos renováveis levará a mais aumentos de preços e escassez. Tocamos aqui nos limites intransponíveis de regimes de crescimento estruturalmente desequilibrados, social e ecologicamente predadores. Um crescimento baseado na guerra econômica e na liberação de $\mathrm{CO} 2$, bloqueando os habitantes no tráfego das megacidades, sufocando-os com gaz de escapamento, degradando sua sociabilidade e solidariedade, envenenando-os com poluições de todos os tipos.

\section{CONCLUSÃO}

Movimentos

"antipolítica"

ou

"manipulados"? O despertar político globalentra em colisão com as decisões da oligárquia num contexto de crescimento capitalista permanentemente bloqueado por seus limites sociais e ecológicos. $\mathrm{O}$ compromisso representativo - passividade política/ crescimento econômico - esta abalado. Minha tese é que a onda de movimentos de multidões democráticas, junho 2013 sendo o episódio mais recente, reflete a abertura de um novo período histórico de aspiração democrática, a Terceira Idade da democracia. Os limites sociais e ambientais para o crescimento capitalista tornam obsoleta a democracia moderna. Abre-se um longo período de pesquisa e inovação social para reconstruir as instituições da economia e da política de modo a torná-las compatíveis com as demandas sociais e 
democráticas apresentadas pelos cidadãos e as restrições ambientais impostas pela natureza.

Esta interpretação enfatiza a profunda unidade destes movimentos, que poderíamos reunir sob o nome comum de movimento das praças ou da democracia real. Ela também ajuda a entender a irritação, os desentendimentos e até mesmo a hostilidade que os movimentos provocaram e continuam provocando na esquerda moderada e radical. Por que eles não entendem que para mudar as coisas, precisamos fortalecer os partidos da esquerda?, dizem muitos militantes.

O antagonismo de muitos cidadãos indignados frente aos partidos políticos de todos os matizes tem alimentado essa tensão. Assim, no Brasil -, mas incidentes semelhantes também ocorreram em muitos outros países - os manifestantes impediram repetidamente militantes do $\mathrm{PT}$, mas também os partidos mais à esquerda (PSOL, PSTU), de se juntarem aos protestos com suas bandeiras. Muitos esquerdistas estão convencidos de que a direita tem manipulado os manifestantes para desviá-los das questões sociais - o preço dos transportes públicos - para a questão da corrupção, alegadamente constrangedora ao governo e ao PT.

Infelizmente, foram o próprio PT e o governo que tinham agendado no Congresso a Emenda Constitucional $n^{\circ} 37$, justamente tomada como alvo pelos manifestantes. Esta emenda escandalosa procurava reduzir os poderes de investigação do Ministério Público para dificultar a repressão da corrupção política; o Congresso finalmente teve que enterrar essa emenda às pressas face ao movimento cidadão.

Também na Turquia, manifestantes atacaram a legislação punitiva que retirou os poderes de regulamentação dos projetos urbanos da União das Câmaras de Engenheiros e Arquitetos turcos: tinha se tornado inconveniente para o poder, uma vez que denunciou a aliança de interesses entre as grandes firmas da construção civil e o governo AKP.

Longe de ser um movimento puramente social (no Brasil) ou verde (na Turquia), que teria sido desviado para assuntos políticos por manipulações reacionárias, os movimentos de junho, no Brasil e na Turquia, eram intrinsecamente social, ambiental e político. O protesto foi contra decisões políticas - aumento do preço das tarifas de ônibus, grandes obras inúteis - tomadas por representantes eleitos organicamente ligados aos grandes interesses econômicos (empresas privadas de transportes urbanos, grandes grupos da construção civil, bancos). Os anseios profundos centravam-se na exigência da democracia real.

Ao contrário do primeiro-ministro turco Erdogan que chamou os manifestantes de terroristas, a presidente Dilma Rousseff mostrou que ela entendeu a natureza do movimento, propondo um referendo sobre a reforma política. A intervenção do povo na rua teria realmente encontrado uma extensão natural no desenvolvimento de uma ampla consulta aos cidadãos e à sociedade civil, rumo a um plano de reforma política que visa quebrar o clientelismo e a corrupção, e fortalecer o controle dos eleitores sobre os representantes eleitos. Projeto que, naturalmente, teria se chocado com os interesses dos parlamentares e, portanto, teria precisado uma aprovação por referendo. Mas os parlamentares e os partidos políticos - inclusive o PT - cortaram imediatamente a vontade presidencial. Não haverá reforma política - não antes que um novo movimento, mais poderoso a torne obrigatória.

E daí? O surgimento dos movimentos desde 2011 reflete uma aceleração deste despertar político global, que faz parte da longa história. Este movimento tem apenas três anos, o que, claro, torna absurda a ideia de fazer seu balanço. Ele tem agora um esboço de identidade própria - os manifestantes espanhóis, tunisinos, egípcios ou americanos trocaram sinais e símbolos - mas não tem estruturas organizacionais específicas, mesmo que ele tenha começado a penetrar nas estruturas do movimento de justiça global (o Fórum Social Mundial - (FSM), que ele continua diretamente. Mas uma coisa é certa: não é um fogo de palha. As raízes do movimento só podem se aprofundar no solo das nossas sociedades afetadas pela crise social, ambiental e democrática, que infelizmente vai piorar nas próximas décadas.

A análise dos movimentos aqui apresentada explica porque os partidos da esquerda radical não se beneficiam mecanicamente. Os cidadãos indignados compreenderam melhor do que a esquerda, a extensão dos problemas colocados pela crise global de hoje. Nem a conquista de cargos dentro de um Estado colonizado pela finança e a corrupção, nem a retomada do crescimento baseado no consumo de automóveis e na exploração irresponsável dos combustíveis fósseis não convencionais, representam alternativas credíveis. A grande maioria dos cidadãos indignados não tem nenhum desejo, compreensivelmente, de participar de organizações de esquerda, impregnadas por uma cultura política estatista e produtivista. Se essas organizações não entenderem que tem obrigação de empreender uma transformação democrática radical, elas vão perder qualquer relevância para a mudança social.

Os movimentos têm a sua dinâmica própria de surgimento e propagação, e os intelectuais não tem muito peso naquilo. No entanto, o seu papel é de fornecer conceitos valiosos, estruturas intelectuais para a interpretação e a sistematização das inovações sociais trazidas pelos movimentos. Assim, a esquerda petista fez uma contribuição significativa na década de 1990 ao inventar o orçamento participativo e ao contribuir decisivamente para o lançamento do FSM. Hoje a criatividade dos movimentos democráticos globais faz com que eles estejam experimentando novas formas políticas e reabilitando antigas, tais como a democracia direta, a rotação dos cargos ou o sorteio, rejeitadas pela democracia moderna 
por seu excesso de radicalidade democrática. Intelectuais democráticos podem ajudar os cidadões a delinear os traços de um mundo onde a fronteira entre dirigentes e dirigidos seria porosa e provisória (mandar obedecendo, como dizem os zapatistas); onde a sociedade teria colocado a economia e a política num caminho sustentável do ponto de vista ecológico e democrático.

\section{REFERÊNCIAS}

BRZEZINSKI, Zbigniew. "The Dilemma of the Last Sovereign", 2005. Disponível em: <http://www.theamericainterest.com/article.cfm?piece=56\#sthash. ephUWOt3.dpuf>. Acesso em: 1 Ago. 2013.

COUTROT, Thomas. Le Troisième Âge de la Démocratie. Mouvements, Paris, nov. 2011. Disponível em: <www.mouvements.info/Letroisieme-age-de-la-democratie.html>. Acesso em: 1 Ago. 2013.

DENOUNE, Martine. Immobilier: les prix flambent dans les pays émergents. Paris, jul., 2013. Disponível em: <mdenoune.wordpress.com/2013/07/16/ immobilier-le-boum-des-prix-dans-les-paysemergents/>. Acesso em: 1 Ago. 2013.

THE new young Turks. The Economist, London, 7 jun. 2013. Disponível em: <http://www.economist. com/news/briefing/21579005-protests-againstrecep-tayyip-erdogan-and-his-ham-fisted-responsehave-shaken-his-rule-and>. Acesso em: 1 Ago. 2013.

\section{NOTAS}

1 Cf. entre outros, CHAUI, Marilena. Pela responsabilidade intelectual e política. Revista Cult, ago. 2013. Disponível em: <revistacult.uol.com.br/ home/2013/08/pela-responsabilidade-intelectual-epolitica/>.

2 A lista dos movimentos é comprida: Tunísia (dez. 2010), Egito e lémen (jan. 2011), Portugal, Síria e Reino-Unido (março 2011), Índia (abril 2011), Espanha, Croácia (maio 2011), Grécia, Senegal (junho 2011), Chile, Israel (julho 2011), EUA (set. 2011), Rússia (dez. 2011), Quebec (fev. 2012), Argentina (nov. 2012), Eslovênia (dez. 2012), Turquia, Bulgária, Brasil (junho 2013).

3 Isso é, sobretudo, o caso nas assembleias populares de bairros que sucedem as grandes manifestações populares ou ocupações (Grécia, Espanha, Portugal, EUA, Turquia...).

4 Particularmente na França graças à inspection des finances, viveiro de ministros, de presidentes da república e de PDG de bancos.
5 Vale a pena citar essa analise lúcida dum dos mais brilhantes ideólogos do imperialismo americano. A elevação dos níveis educativos, "o acesso univeral à radio e à televisão e cada vez mais à internet" criam "uma população que tem uma consciência aguda, nunca alcançada na historia, da injustiça social", "uma massa gigantesca de jovens impacientes"; e, podemos acrescentar, altamente preocupados com a irresponsabilidade ecológica das elites.

6 Montesquieu escreveu: "[...] o sufrágio pela sorte é da natureza da democracia; o sufrágio pelo voto é da democracia". A eleição dá para os "melhores" o direito de governar a "massa", o que é a essência da aristocracia.

7 Rousseau dizia que a soberania não pode ser representada.

8 Essa tendência geral foi recentemente interrompida no Brasil, onde a participação dos salários tem aumentado ligeiramente entre 2004 e 2010.

\section{Thomas Coutrot}

Economista

Ministério do Trabalho e Emprego na França

E-mail: thomas.coutrot@dares.travail.gouv.fr

Association pour la Taxation des Transactions Financières et pour l'Action Citoyenne-France 26 rue Malot 93100 Montreuil

France 